\title{
Editorial
}

\section{Obesity as collateral damage: A call for papers on the Obesity Epidemic}

\author{
Journal of Public Health Policy (20II) 32, I43-I45. doi:IO.IO57/jphp.20II.I4
}

In this call for papers, we encourage authors to submit articles considering how to change the behavior of the food industry. Here's why.

Since we published the Special Section on Legal Approaches to the Obesity Epidemic from the Public Health Advocacy Institute in 2004, ${ }^{1}$ the Journal has fully engaged in debates over obesity - its causes and how to prevent it. (The JPHP website displays a collection of articles on nutrition and obesity at http://www.palgrave-journals.com/jphp/ collections/food_and_obesity_collection.html.) Obesity surely constitutes an epidemic - a global phenomenon, seen in low income, as well as affluent countries. It often coexists with hunger and malnutrition. What are the underlying, root causes of obesity and its public health consequences?

We know that almost every country has created policies to prepare for and to avoid famine and food shortages that might damage their people, and disrupt their economies and social fabric. In 20I0, Russia blocked wheat exports when bad weather destroyed its crops. The United States government, since early in the last century, has supported food production through subsidies and other policies, resulting in large surpluses of food commodities, meat, and calories. These policies maintain the price of food at artificially low levels and have reduced the percentage of personal income spent on food to the lowest in the world.

In this artificial market, large food producers and corporations Big Agriculture and Big Food - became very profitable. The first set of countries to experience economic concentration, starting before the Great Depression - the United States, Japan, and countries in Europe - found that just a few corporations came to dominate each segment of the food industry. These firms integrated vertically to the point where they now own, and increase their profitability from, every step in the chain of production from farms to wholesale distribution of processed foods. In the past 30 years in the United States, for example, consolidation by corporations means that the number of separately owned hog farms decreased by nearly 90 per cent, and only four per cent of the millions of hogs raised by US 
farmers are ever sold on the open market. ${ }^{2}$ Today, US farms and farmers contribute only a small part of the final 'value' of food; what is raised on farms costs only 20 cents of the food dollar, on average. ${ }^{3}$ The rest is 'value added' in the remaining steps in the chain: supply, distribution, and marketing. This explains why companies seek vertical integration; and why they manufacture so many processed foods. The first reduces cost of inputs and the second introduces opportunities to increase the value or price of the consumer product.

The processed foods that reach US consumers, and increasingly people in all high-income countries, are remarkably inexpensive, tasty, and convenient to prepare. They are intensely marketed and highly profitable to corporate producers. Where does the profit come from? In part, it comes from use of subsidized commodities. But profits are also generated by capturing increasingly larger shares of the market and by selling the population more food - and calories than it needs. In this marketing environment, obesity is collateral damage.

The food industry's ultimately anti-social behavior - whether conscious or inadvertent - is spreading globally. In higher income countries, it is ubiquitous, whereas in places where people have less disposable income, it is but the camel's nose under the tent. Thus, effective strategies to reduce obesity may vary depending on penetration by the industry - and less developed nations may still have more opportunities to avoid obesity, by getting ahead of the curve.

Signs of marketing efforts by multi-national food corporations are appearing everywhere in developing countries. In 2010, The New York Times reported that international sales accounted for half of PepsiCo's revenue, whereas three-fourths of Coca-Cola sales occur outside the United States; both companies are US corporations. Kraft (also in the United States) reported a tripling of profits on the strength of overseas markets. And the world's largest food company, Nestle, headquartered in Switzerland, with US \$IOI billion in sales, is omnipresent. Rates of obesity are climbing so rapidly in the developing world that the phenomenon has gained its own name: the nutrition transition.

The tobacco analogy: this industry, which deliberately encouraged children to become addicted to cigarettes as early as possible, then continued to market cigarettes even once well aware of the health dangers. We now know the health dangers of obesity, but the 
epidemic continues. To protect the public, perhaps we can learn from anti-smoking efforts about means to constrain the food industry. ${ }^{4}$

As public health advocates, we know all too well that teaching the world's population about the dangers of obesity and the need to avoid obesogenic foods that are inexpensive, tasty, and convenient, will never work if food corporations are permitted to continue to spend massively to encourage the public to eat more of their products. Efforts to control obesity will have to enlist the public to focus on behavior, with a shift from a sole focus on citizens to a new one on the behavior of food corporations.

Food is not cigarettes. We must eat to live. We cannot eliminate the food industry to reverse the obesity epidemic, but we can constrain its anti-social behavior. This Editorial is posted on JPHP's website as a call for papers. We encourage authors to reach beyond the kind studies of policies on eating and activity that we receive so frequently. We have come to believe that research studies concentrating on personal behavior and responsibility as causes of the obesity epidemic do little but offer cover to an industry seeking to downplay its own responsibility.

Instead, we urge authors to submit articles that consider how to understand and change the behavior of the food industry. As a starting point for thinking about how to approach this topic, we ask: does the industry need to overfeed the population to remain profitable?

\title{
References
}

I. Journal of Public Health Policy. (2004) Special issue section: Legal approaches to the obesity epidemic 25(3-4): 346-434.

2. New York Times (20I0) Editorial: Reforming meat. 7 September, http://www.nytimes.com/ 2010/o9/o8/opinion/o8wed $3 . h t m l$ ?scp=9\&sq=hog\% 2 oproduction\&st=cse.

3. USDA. (2008) Briefing room: Food marketing system in the U.S.: Price spreads from farm to consumer, http://www.ers.usda.gov/Briefing/FoodMarketingSystem/pricespreads.htm, accessed February 2OII.

4. Brownell, K.D. and Warner, K.E. (2009) The perils of ignoring history: Big tobacco played dirty and millions died. How similar is big food? The Milbank Quarterly 87(I): 259-294.

\author{
Anthony Robbins \\ Co-Editor, \\ E-mail: anthony.robbins@tufts.edu \\ Marion Nestle \\ Editorial Board Member, \\ E-mail: marion.nestle@nyu.edu
}

